\title{
Temporal and Spatial Distribution of $\mathrm{SO}_{2}$ in the Process of Haze in North China Based on Remote Sensing Data
}

\author{
Chang Ruoying, Zhao Jun*, Li Wen, Jia Jingjing \\ College of Geography and Environmental Science, Northwest Normal University, Lanzhou, China \\ Email address: \\ 18435122420@163.com (Chang Ruoying), zhaojun $a$ nwnu.edu (Zhao Jun) \\ ${ }^{*}$ Corresponding author
}

To cite this article:

Chang Ruoying, Zhao Jun, Li Wen, Jia Jinging. Temporal and Spatial Distribution of $\mathrm{SO}_{2}$ in the Process of Haze in North China Based on Remote Sensing Data. International Journal of Environmental Monitoring and Analysis. Vol. 7, No. 1, 2019, pp. 27-33.

doi: 10.11648/j.ijema.20190701.14

Received: April 21, 2019; Accepted: May 22, 2019; Published: June 15, 2019

\begin{abstract}
Based on the data sources of OMI data and haze data in North China, this paper studies the spatial distribution characteristics of $\mathrm{SO}_{2}$ column amounts in North China from 2015 to 2017, and compares the relationship between $\mathrm{SO}_{2}$ column amounts and haze. Corresponding analysis reveals the objective regularity of its existence. The results revealed that: 1) spatially, the value of $\mathrm{SO}_{2}$ column is distributed higher in south and lower in north. In time, the amount of $\mathrm{SO}_{2}$ column is characterized by winter $>$ autumn $>$ spring $>$ summer; 2) during the haze event, $\mathrm{SO}_{2}$ increased first and then decreased. The correlation analysis between the monthly average concentration of $\mathrm{SO}_{2}$ and the frequency of haze weather, showed that there is a high correlation between the $\mathrm{SO}_{2}$ concentration and the frequency of haze occurrence, and there is consistency in the space-time distribution; 3) The haze in North China is affected by meteorological and climatic factors and human activities. Coordination within the region is an important means to control air quality. To clarify the spatial and temporal distribution of $\mathrm{SO}_{2}$ during the haze weather in North China is conductive to smooth progress of haze events control in North China.
\end{abstract}

Keywords: Atmospheric Remote Sensing, $\mathrm{SO}_{2}$, Haze, North China

\section{Introduction}

Sulfur dioxide $\left(\mathrm{SO}_{2}\right)$, a common sulfur oxide, is one of the major pollutants in the atmosphere. Sulfur dioxide in the atmosphere can form sulfuric acid mist or sulphate aerosol by oxidation and moisture in the air that reduce visibility, affect cloud formation, and lead to acid rain and deposition, is an important precursor of environmental acidification. [1] It is one of the influencing factors leading to the occurrence of haze and it has significant impacts on the environment and climate at global. [2] It is very serious impact to human production, life and health. Anthropogenic sources of $\mathrm{SO}_{2}$, consisting primarily of fossil fuel burning, metal smelting, and oil and gas refining. The remainder of $\mathrm{SO}_{2}$ emissions come from natural sources volcanic eruptions and degassing and sea spray. [3-5]

Haze, also known as ash, refers to the phenomenon that the air formed by a large amount of smoke, fine particles, water vapor in the air, and other non-aqueous substances is generally turbid. Haze weather will affect traffic, increase air pollution, and even pose a threat to human health, seriously affecting production and life. [6] In the past 10 years, due to the rapid expansion of the economic scale and the acceleration of industrialization and urbanization, the haze in North China has occurred frequently, which has aroused widespread concern in all walks of life.

In recent years, domestic and foreign scholars have done a lot of research on the $\mathrm{SO}_{2}$ and haze. Studies have shown that the $\mathrm{SO}_{2}$ amounts in China is increasing year by year, and the distribution is higher in the east than in the west, and the industrial area is higher than the non-industrial area, at the same time, haze events in China is increasing and more persistent. [7-8] By identifying the high-intensity haze in the country, it is found that the haze often in winter, and the high-incidence areas include the Beijing-Tianjin-Hebei region, the Yangtze River Delta, the Pearl River Delta and some urban economic belt, the most typical and most influential area is the Beijing-Tianjin-Hebei region.[9-10] The reason of the frequent causes of haze, it is related to the a 
large number of pollutants emission and to the meteorological and climatic conditions of the area. [11-14]

This paper attempts to use the OMI data to retrieve the $\mathrm{SO}_{2}$ column amounts product data, and to analyze the temporal and spatial distribution of $\mathrm{SO}_{2}$ column amounts during the haze in North China from 2015 to 2017, and to reveal the objective relationship between them.

\section{Data and Methods}

North China includes the city of Beijing, the city of Tianjin, Hebei province, Shanxi province, and Inner Mongolia autonomous region, and covers an area of 1,565,900 $\mathrm{km}^{2}$. The population was approximately 174.79 million by the end of 2017. North China is an important center of administrative, economic and cultural. The southeastern part of the region belongs to the North China Plain, with flat terrain, multiple beaches and wetlands along the coast; the southwest belongs to the Loess Plateau, with high terrain and degree of relief is large; the northern part is the Inner Mongolia Plateau with undulating terrain; the climate is temperate continental monsoon climate with four distinct seasons. Spring is characterized by warm and cold, high temperature and rainy in summer, pleasantly cool and dry in autumn, and cold and dry in winter. [15]

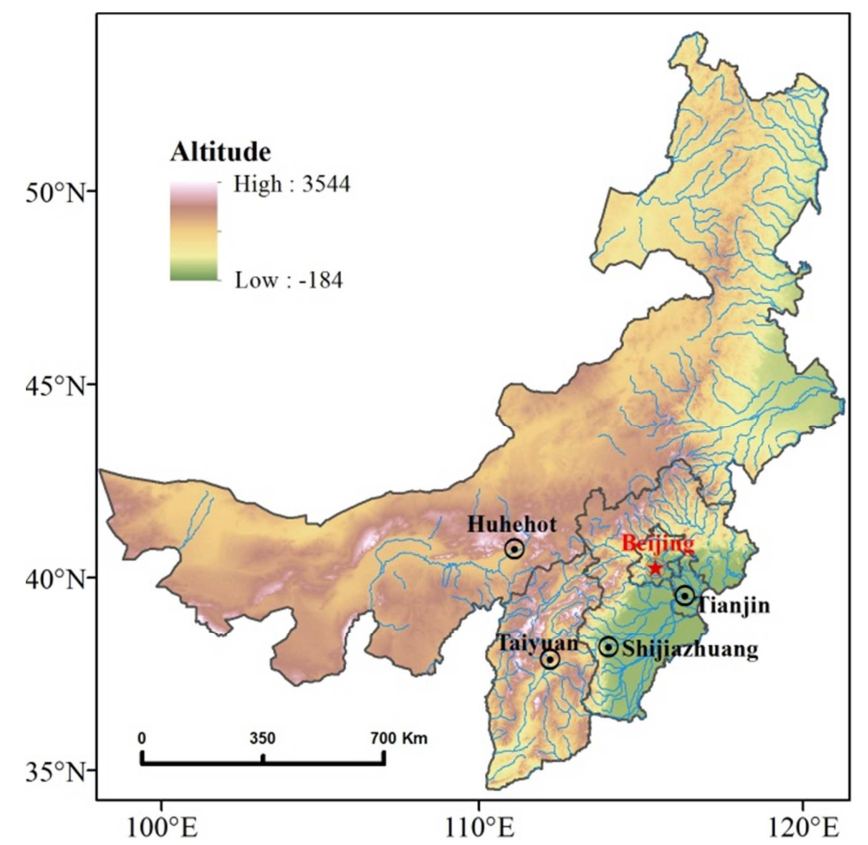

Figure 1. The geomorphologic map of the North China region.

\subsection{Data}

The Ozone Monitoring Instrument (OMI) is a trace gases detector mounted on the Aura satellite and was jointly developed by the National Aeronautics and Space Administration (NASA) and the Finnish Meteorological Society (FMI). The Level-2 OMSO2 data from the NASA
GES DISC database (http://mirador.gsfc.nasa.gov/) is used. It can be collected for free on the official website. This data reflects the atmospheric boundary layer SO2_PBL (Column Amount SO2_PBL), which is mainly used for the study of $\mathrm{SO}_{2}$ pollution in near-surface atmosphere. [16]

\subsection{Methods}

The unit for trace gases in the atmosphere by satellite is Dobson Unit (DU). The unit of $\mathrm{SO}_{2}$ concentration in the Chinese Climate Gazette is $\mu \mathrm{g} / \mathrm{m}^{3}$. The two units are not uniform when comparing together. Therefore, the remote sensing data and the ground observation data are normalized and dimensionless. [17] Formula is as follows:

$$
Y_{i}=\frac{X_{i}-\min \left\{X_{i}\right\}}{\max \left\{X_{i}\right\}-\min \left\{X_{i}\right\}}
$$

Where $\mathrm{Y}_{i}$ is nondimensionalize data; $\mathrm{X}_{i}$ is unprocessed raw data.

VASAN software is used to convert Level-2 OMSO2 data to shapefile data. This paper filters the study area and sets the cloud parameter to 0.3 to obtain the $\mathrm{SO}_{2}$ vertical column amounts. The Kriging method is used to rasterize the $\mathrm{SO}_{2}$ shapefile data to obtain $0.125^{\circ} \times 0.125^{\circ}$ raster data.

\section{Result and Discussion}

\subsection{Temporal and Spatial Distribution Characteristics of $\mathrm{SO}_{2}$ Column}

OMI data were used to calculate the average annual $\mathrm{SO}_{2}$ distribution of the planetary boundary Layer in North China during 2015-2017 (Figure 2). Figure 2 shows that the distribution of $\mathrm{SO}_{2}$ annual column amounts in the planetary boundary layer in North China is uneven, with high in the southeast, slightly higher in the north, and lower in the middle. Among them, the $\mathrm{SO}_{2}$ annual column amounts of the North China Plain is significantly higher than other areas; the $\mathrm{SO}_{2}$ column amounts has a tendency to decrease year by year.

Affected by regional emissions and climatic factors, the $\mathrm{SO}_{2}$ column has obvious seasonal variation. According to the distribution of $\mathrm{SO}_{2}$ monthly average column amounts in North China from 2015 to 2017 (Figure 3), the $\mathrm{SO}_{2}$ column in North China is the highest in winter, followed by spring and autumn, and lowest in summer. The maximum amounts appears in December, and the minimum in June; the annual change is U-shaped.

The reason for the high amounts of $\mathrm{SO}_{2}$ column in winter in this area is that in the winter heating period, the consumption of coal and natural gas increases, and the $\mathrm{SO}_{2}$ emission increases accordingly. Second, the winter climate is dry and less rain, which makes it easy for $\mathrm{SO}_{2}$ to stay in the air for a long time. 


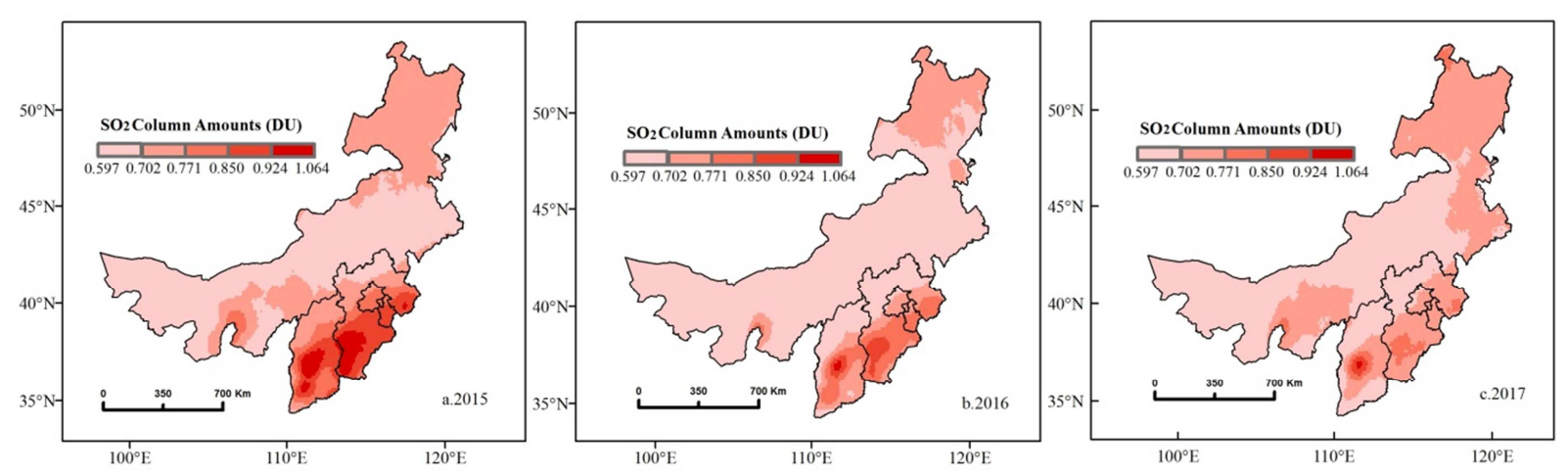

Figure 2. Spatial distribution of average annual $\mathrm{SO}_{2}$ column amounts in 2015-2017.

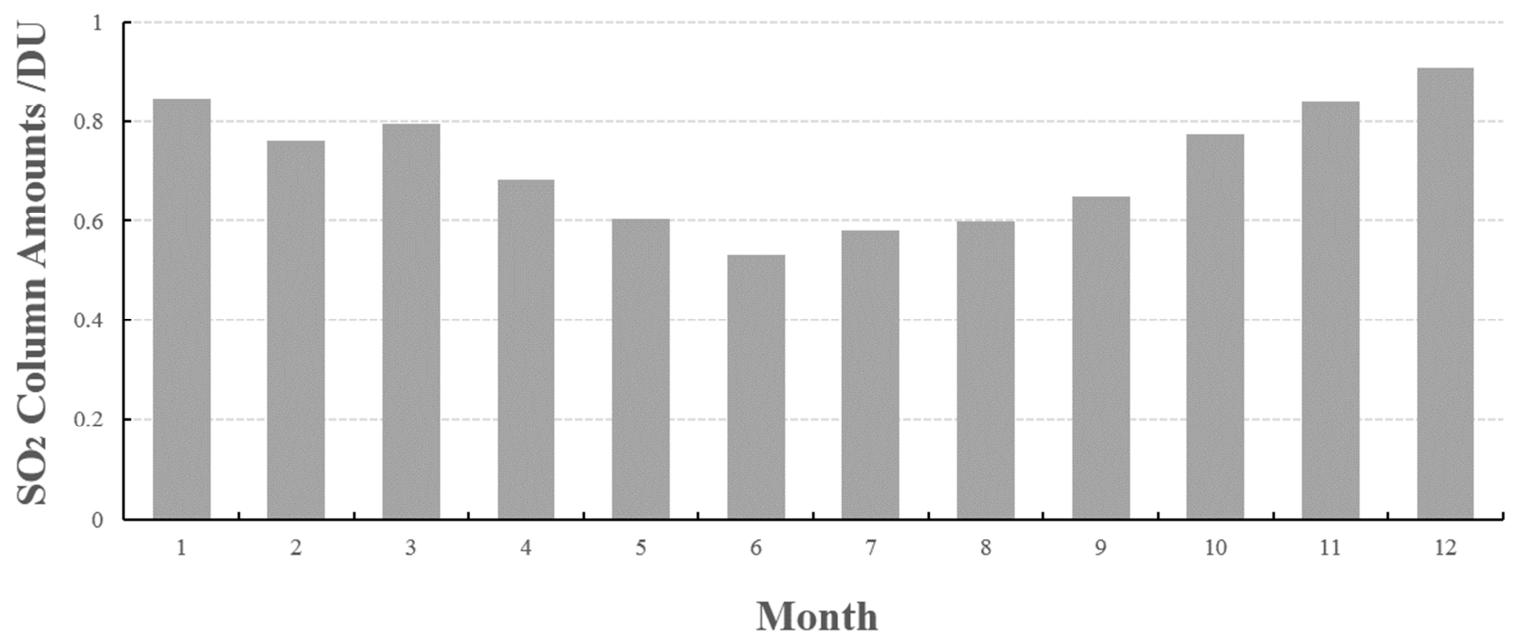

Figure 3. the average monthly of $\mathrm{SO}_{2}$ column in the North China in 2015-2017.

\subsection{Temporal and Spatial Distribution Characteristics of Haze}

According to the 2015-2017 China Climate Bulletin issued by the China Meteorological Administration, there are eleven large-scale and persistent haze events over China in 2015, 8 times in 2016 and 5 times in 2017. High-intensity haze has appeared each year from 2015 to 2017 , which not only lasts for a long time, has high intensity, but has a wide range of influences and rapid development of the process. It is accompanied by the combination of strong fog and severe aerosol, low visibility and serious pollution.
According to the environmental bulletin of the five provinces of North China in 2015-2017, the frequency of haze events has the characteristics of winter $>$ autumn $>$ spring $>$ summer, and is most concentrated in November, December and January. At the same time, the frequency of haze events in the five provinces varies (Figure 4). The frequency of haze in Hebei, Beijing and Tianjin is higher, and that in Inner Mongolia is lower, which is consistent with the annual average spatial distribution of $\mathrm{SO}_{2}$, and the overall is high in the south and low in the north.

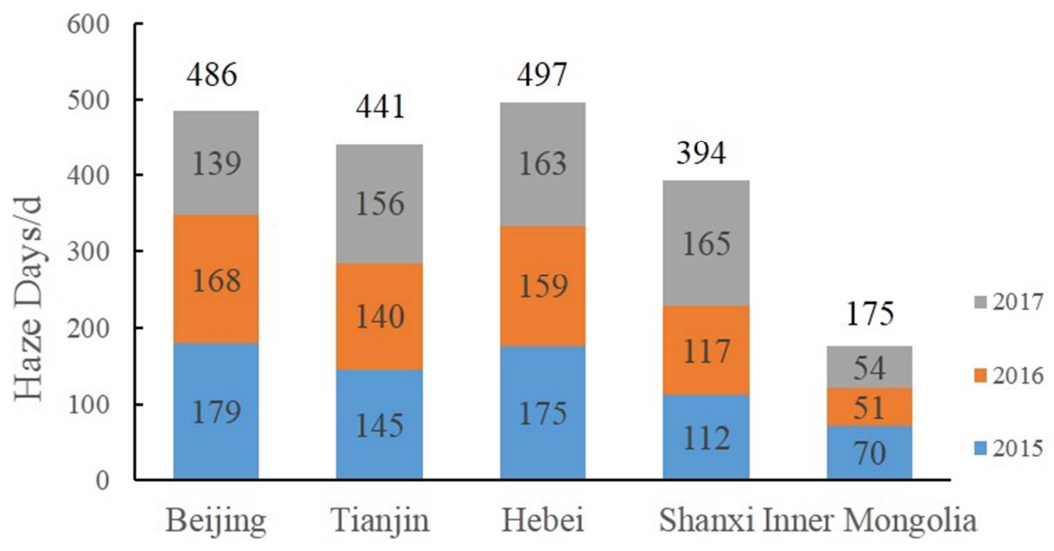

Figure 4. 2015-2017 haze days in each province. 


\subsection{Correlation Analysis Between Haze Events and $\mathrm{SO}_{2}$ Column}

According to the 2015 National Climate Bulletin issued by the China Meteorological Administration, large-scale and persistent haze events occurred in most parts of North China from Nov of 2015 to Jan of 2016. Figure 5 is a broken line diagram showing the variation of $\mathrm{SO}_{2}$ column amounts during the haze events in winter of 2015 . Figure 5 shows that there were 11 haze occurrences in the winter of 2015. During the haze, the $\mathrm{SO}_{2}$ column amounts began to increase with the occurrence of haze, and then decreased after reaching the peak until the end of the events. The overall change was first increased and then decreased. At the same time, during the occurrence of persistent haze, the amounts of the $\mathrm{SO}_{2}$ column will change continuously as the haze continues to form several peaks.

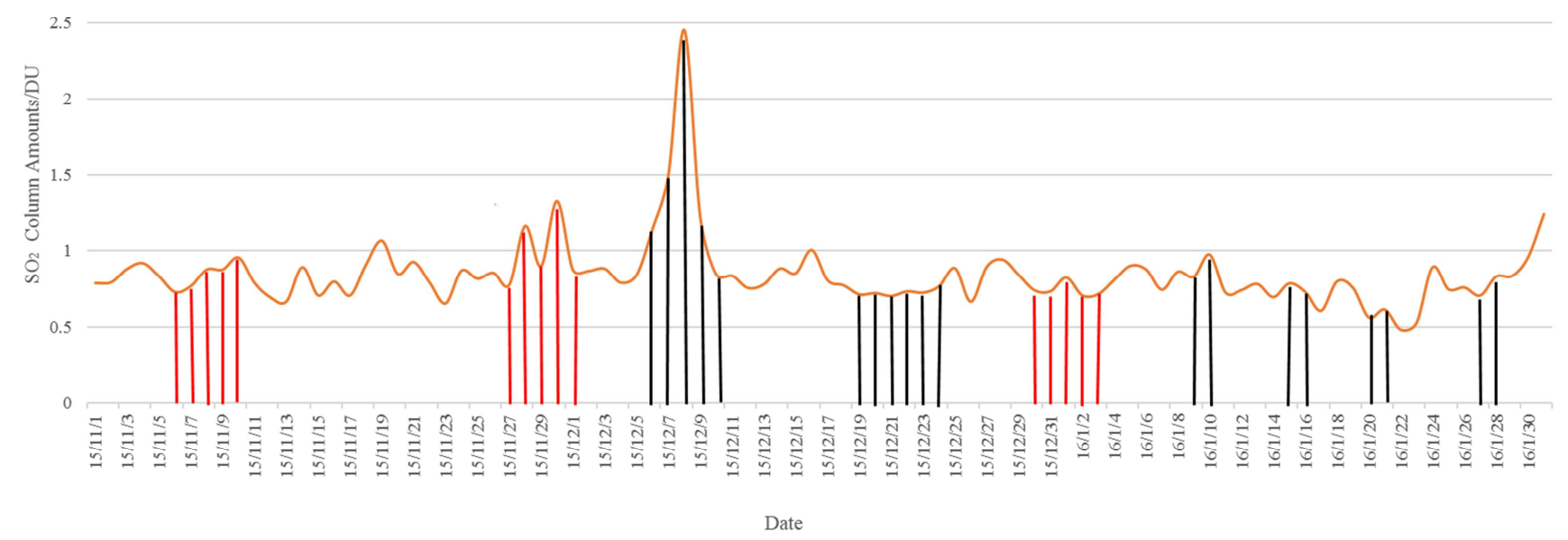

Figure 5. Changes in SO2 column amounts during severe haze during the winter of 2015.

The reason for the change of $\mathrm{SO}_{2}$ column amounts during haze is that the $\mathrm{SO}_{2}$ in the initial phase of haze beginning creases greatly in natural conditions, and the $\mathrm{SO}_{2}$ concentrations increases; then a large amount of $\mathrm{SO}_{2}$ reacts with ultraviolet rays in sunlight to generate a large number of secondary pollutants (eg. Sulfate, sulfite), and led to secondary aerosol formation, suspended in the air, which results the reduction of visibility and the aggravation of haze.[18] In the case of weak illumination, $\mathrm{SO}_{2}$ interacts with water molecules in the atmosphere, competing with water to adsorb, and synergistically acts on the oxidation of $\mathrm{SO}_{2}$. The formation of suspended matter leads to further worsen of haze.

Taking Beijing city, Tianjin city and other provincial capitals as examples, this paper calculates the monthly average concentrations of $\mathrm{SO}_{2}$ at each site, and the number of days of haze events in each month, then analyzes the statistically relationship between them. The results are showed as follows (Table 1). Table 1 demonstrates significantly positive correlation between $\mathrm{SO}_{2}$ concentrations and the amounts of haze events. Except for Hohhot, which is moderately correlated, the other four cities are highly positively correlated.

Table 1. Linear regression results of $\mathrm{SO}_{2}$ column concentration and monthly haze days.

\begin{tabular}{llllll}
\hline & Beijing & Tianjin & Shijiazhuang & Taiyuan & Huhehot \\
\hline $\mathrm{R}^{2}$ & 0.5623 & 0.6337 & 0.6401 & 0.6324 & 0.394 \\
Coefficient & 1.0557 & -1.18 & -1.9426 & -1.5734 & -0.4566 \\
Slope & 0.4126 & 0.2266 & 0.2258 & 0.0792 & 0.064 \\
\hline
\end{tabular}

\subsection{Analysis of the Causes of Haze in Winter}

Studies have shown that the haze in autumn and winter in North China is severe, mainly related to the meteorological and climatic conditions of the region and the anthropogenic pollutant emissions in the region. [19-24] The following two aspects are studied separately.

\subsubsection{Meteorological Factors}

As a weather phenomenon, haze occurrences and develops depend to the degree of dilution and diffusion of pollutants by the atmosphere, which is related to the regional atmospheric circulation and the large-scale climate background. Take the example of the intensity of the haze in the central and southern parts of the North China region from Dec 30, 2016 to Jan 7, 2017, Figure 6 shows the 500hpa synthetic wind (unit: $\mathrm{m} / \mathrm{s}$ ) Geopotential height (unit: hpa) from Decr 2016 to Feb 2017. [25] 


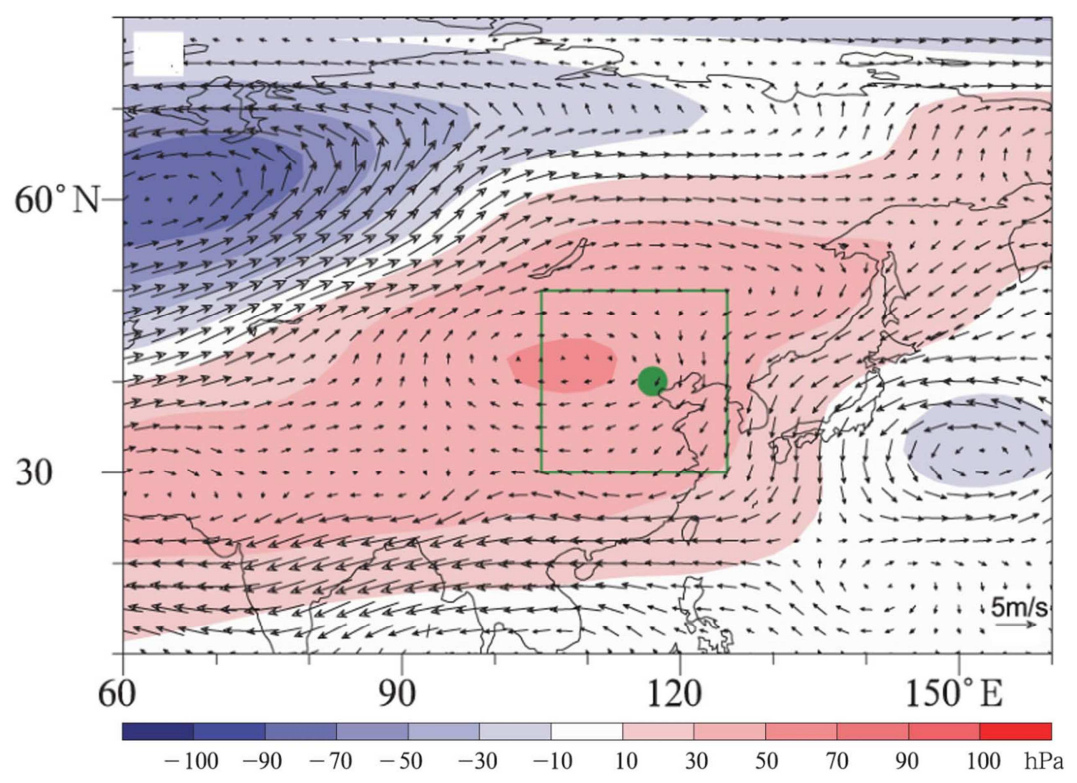

(The green rectangle in the picture indicates "North China", and the green point is Beijing's latitude and longitude: $40^{\circ} \mathrm{N}, 117^{\circ} \mathrm{E}$ )

Figure 6. Composite wind (unit: $\mathrm{m} / \mathrm{s}$ ) and geopotential height (unit: hpa) at $500 \mathrm{hpa}$.

It can be seen from the Figur that the atmosphere in North China is in a static condition, the wind speed near the surface is reduced and the pressure gradientforce is low. In the autumn and winter seasons in North China, there is low temperature, dry and less rain, and the winter monsoon is prevalent. The area is located west of Taihang Mountain and east of Bohai Bay, the winter monsoon is blocked by the Taihang Mountains, led to the reduction of the wind speed, which is not conducive to the diffusion of $\mathrm{SO}_{2}$ and will cause the concentrated accumulation of $\mathrm{SO}_{2}$. As a result, the $\mathrm{SO}_{2}$ column is too high. [26] At the same time, the easterly airflow from the sea brings a lot of water steam, which makes a higher near-surface humidity and a lower visibility, and the $\mathrm{SO}_{2}$ concentration rises sharply, which aggravates the pollution situation.

\subsubsection{Human Factors}

Anthropogenic emissions are another important reason for increasing the accumulation of haze and $\mathrm{SO}_{2}$. For example, during the period of "The Chinese People's Anti-Japanese War and the 70th Anniversary of the Victory of the World Anti-Fascist War" held in Beijing on September 3, 2015, in order to ensure the succeed celebrate of the military parade and the air quality in the surrounding areas, the relevant departments from August began to take extremely strict pollution control measures on the surrounding areas of Beijing, strictly control various pollutants emissions.

This paper selects the concentration of major pollutants in the early stage of the military parade, the period of emission reduction, the day of the military parade and the later period of military parade. The results are shown in Table 2.

Table 2. The concentration of pollutants in the air quality control before, during and after the air quality of the parade is compared.

\begin{tabular}{lllll}
\hline & Earlier stage & Emission reduction period & Activity day & Later stage \\
\hline Times & $08.01 \sim 08.19$ & $08.20 \sim 09.03$ & 09.03 & $09.04 \sim 09.18$ \\
$\mathrm{PM}_{2.5}\left(\mu \mathrm{g} / \mathrm{m}^{3}\right)$ & 60.95 & 17.93 & 15.00 & 50.80 \\
$\mathrm{PM}_{10}\left(\mu \mathrm{g} / \mathrm{m}^{3}\right)$ & 86.53 & 32.2 & 30.00 & 64.73 \\
$\mathrm{CO}\left(\mathrm{mg} / \mathrm{m}^{3}\right)$ & 0.93 & 0.55 & 0.50 & 0.83 \\
$\mathrm{NO}_{2}\left(\mu \mathrm{g} / \mathrm{m}^{3}\right)$ & 36.21 & 22.73 & 19.00 & 42.47 \\
$\mathrm{SO}_{2}\left(\mu \mathrm{g} / \mathrm{m}^{3}\right)$ & 3.84 & 2.33 & 2.00 & 4.8 \\
\hline
\end{tabular}

Table 2 shows that the concentration of air pollutants change, the concentrations of $\mathrm{PM}_{2.5}$ and $\mathrm{PM}_{10}$ decrease by $75.39 \%$ and $65.33 \%$, and the other three pollutants decrease by $46.24 \%, 47.53 \%$, and $47.91 \%$. The sources of these air pollutants are mostly fossil fuel burning, industrial processes and contrived production emission. On the day of the military parade, the concentration of various pollutants is lowest. Simultaneously, the air quality in Beijing, Tianjin, Hebei and other places shows an excellent grade. However, after the military parade, the control measures were abolished, and the concentration of pollutants rose again. $\mathrm{SO}_{2}$ and $\mathrm{NO}_{2}$ rebounded the most, even exceeding the pre-reduction period, indicating that human activities have a significant impact on the air quality in North China, artificial control of emission reduction can effectively improve the region air quality.

\section{Conclusion}

1. There is a significant spatial difference between the $\mathrm{SO}_{2}$ column amounts and the times of haze in North China. 
The overall is high in the south and low in the north. The $\mathrm{SO}_{2}$ column amounts and the haze events in the North China Plain are the highest; the $\mathrm{SO}_{2}$ concentration and the frequency of haze occurrence for winter $>$ autumn $>$ spring $>$ summer. They are consistent in time.

2. The $\mathrm{SO}_{2}$ change during haze has a significant correlation with the haze process; in the continuous haze process, multiple peaks appear in the $\mathrm{SO}_{2}$ column. Correlation analysis shows that the $\mathrm{SO}_{2}$ concentration has a high positive correlation with the frequency of haze, and $\mathrm{SO}_{2}$ is also one of the important factors leading to the further increase of haze.

3. The wind speed is small in autumn and winter in North China, and the air pressure is stable, which is not conducive to the diffusion of $\mathrm{SO}_{2}$ and easy to form haze. At the same time, the artificially $\mathrm{SO}_{2}$ emission in North China is too high, resulting in an increase in the frequency of haze and a large number of severe haze.

4. With the introduction of more and more air pollution control policies, the amounts of $\mathrm{SO}_{2}$ column in North China has been decreasing year by year.

\section{Acknowledgements}

The DEM data used for topography is derived from http://www.gscloud.cn/. The ground observation data in this paper is from https://www.aqistudy.cn/. The data on the occurrence of the haze events comes from the Environmental Climate Bulletin (2015-2017) issued by the China Meteorological Administration.

\section{References}

[1] Fioletov, V. E., McLinden, C. A., Krotkov, N, et al. Lifetimes and emissions of $\mathrm{SO}_{2}$ from point sources estimated from OMI [J]. Geophysical Research Letters, 2015, 42 (6): 1969-1976.

[2] Li C, Joiner J, Krotkov N A, et al. A fast and sensitive new satellite $\mathrm{SO}_{2}$ retrieval algorithm based on principal component analysis: Application to the ozone monitoring instrument [J]. Geophysical Research Letters, 2013, 40 (23): 6314-6318.

[3] Fioletov, V. E., McLinden, C. A., Krotkov, N, et al. A global catalogue of large $\mathrm{SO} 2$ sources and emissions derived from the Ozone Monitoring Instrument [J]. Atmospheric Chemistry and Physics, 2016, 16 (18), 11497-11519.

[4] Zhang Y, Li C, Krotkov N A, et al. Continuation of long-term global $\mathrm{SO}_{2}$ pollution monitoring from OMI to OMPS [J]. Atmospheric Measurement Techniques, 2017, 10 (4): 1-21.

[5] Fioletov V E, Mclinden C A, Krotkov N, et al. A global catalogue of large $\mathrm{SO}_{2}$ sources and emissions derived from the Ozone Monitoring Instrument $[\mathrm{J}]$. Atmospheric Chemistry and Physics, 2016, 16 (18): 11497-11519.

[6] Gao M, Guttikunda S K, Carmichael G R, et al. Health impacts and economic losses assessment of the 2013 severe haze event in Beijing area $[\mathrm{J}]$. Science of The Total Environment, 2015, 511: 553-561.
[7] Gao Y B, Mei S Y, Ma J J, et al. Spatiotemporal Variations of $\mathrm{SO}_{2}$ over China by OMI Observations During 2005 2012 [J]. Journal of Atmospheric \& Environmental Optics, 2016.

[8] Zhao J, Zhang B C, Fan J P, et al. The Analysis of $\mathrm{SO}_{2}$ Value Changes in the Atmospheric Boundary Layer over Lanzhou and Surrounding Areas based on the OMI Product [J]. Remote Sensing Technology and Application, 2011, 26 (6): 808-813.

[9] Wu P, Ding Y H, Liu Y J et al. Influence of the East Asian winter monsoon and atmospheric humidity on the wintertime haze frequency over central-eastern China [J]. Acta Meteorologica Sinica. 2016, 74 (3): 352-366.

[10] Zhang Y J, Zhang P Q, Wang J, et al. Climatic Characteristics of Persistent Haze Events over Jingjinji During 1981 - 2013 [J]. Meteorological Monthly. 2015, 41 (3): 311-318.

[11] $\mathrm{Wu} \mathrm{D}, \mathrm{Wu} \mathrm{X} \mathrm{J,} \mathrm{Li} \mathrm{F,} \mathrm{et} \mathrm{al.} \mathrm{Temporal} \mathrm{and} \mathrm{spatial} \mathrm{variation} \mathrm{of}$ haze during 1951-2005 in Chinese mainland [J]. Acta Meteorologica Sinica. 2010, 68 (5): 680-688.

[12] Wu P, Ding Y H, Liu Y J. Atmospheric circulation and dynamic mechanism for persistent haze events in the BeijingTianjin-Hebei region [J]. Advances in Atmospheric Sciences, 2017, 34 (4): 429-440.

[13] Ding Y H, Wu P, Liu Y J, et al. Environmental and Dynamic Conditions for the Occurrence of Persistent Haze Events in North China [J]. Engineering, 2017, 3 (2): 266-271.

[14] Wang Y S, Liu Z R, Ji D S, et al. Formation of haze pollution in Beijing-Tianjin-Hebei region and their control strategies [J]. Bulletin of Chinese Academy of Sciences, 2013 (3): 353-363.

[15] Krotkov N A, Carn S A, Krueger A J, et al. Band residual difference algorithm for retrieval of $\mathrm{SO}_{2}$ from the aura ozone monitoring instrument (OMI)[J]. IEEE Transactions on Geoscience \& Remote Sensing, 2006, 44 (5): 1259-1266.

[16] Livingston J M, Redemann J, Russell P B, et al. Comparison of aerosol optical depths from the Ozone Monitoring Instrument (OMI) on Aura with results from airborne sunphotometry, other space and ground measurements during MILAGRO/INTEX-B [J]. Atmospheric Chemistry \& Physics, 2009, 9 (2): 537-540.

[17] Kang C Y, Zhao J, Song G F, et al. Study on the spatial of $\mathrm{SO}_{2}$ in China's atmospheric boundary layer based on OMI data [J]. China Environmental Science. 2018, 38 (2): 435-443.

[18] Liu W J, Han Y X, Wang J, et al. Aerosol optical properties during one typical haze event over October 2010 in Beijing [J]. China Environmental Science, 2015, 35 (07), 1931-1937.

[19] Fedkin, N., Li C., Dickerson R·Dickerson., et al. Linking improvements in sulfur dioxide emissions to decreasing sulfate wet deposition by combining satellite and surface observations with trajectory analysis. [J] Atmospheric Environment. 2018. 11. 039

[20] Wang H J, Chen H P, Liu J P. Arctic Sea Ice Decline Intensified Haze Pollution in Eastern China [J]. Atmos Ocean Sci Lett. 2015, 8 (1): 1-9.

[21] Pei L, Yan Z, Sun Z, et al. Increasing persistent haze in Beijing: potential impacts of weakening East Asian winter monsoons associated with northwestern Pacific sea surface temperature trends $[\mathrm{J}]$. Atmospheric Chemistry and Physics, 2018, 18 (5): 3173-3183. 
[22] Zhou J B, Li Z G, Lu N, et. al. Online Sources about Atmospheric Fine Particles During the 70th Anniversary of Victory Parade in Shijiazhuang [J]. Environmental Science. 2016, 37 (8): 2855-2862.

[23] Wang L, Hu B, Mao G, et al. Impact of emission controls on air quality in Beijing during APEC 2014: lidar ceilometer observations [J]. Atmospheric Chemistry and Physics, 2015, 15 (9): 13173-13209.

[24] Wang L T, Wei Z, Yang J, et al. The 2013 severe haze over southern Hebei, China: model evaluation, source apportionment, and policy implications $[\mathrm{J}]$. Atmospheric Chemistry and Physics, 2014, 14 (6): 3151-3173.

[25] Yan Z W, Pei L, Zhou T J, et al. Unusually clear sky in Beijing during winter 2017 and the underlying large-scale climatic anomalies: With implication for "haze-climate" study [J]. Acta Meteorologica Sinica, 2018, 76 (05): 156-163.

[26] Calkins C, Ge C, Wang J, et al. Effects of meteorological conditions on sulfur dioxide air pollution in the North China plain during winters of 2006-2015 [J]. Atmospheric Environment, 2016, 147: 296-309. 